\title{
Güç Sistemlerinde Geçici Hal Kararsızlığının Arıza Öncesi Fazör Ölçümleri Kullanarak Karar Ağacı Tabanlı Kestirimi
}

\author{
Can Berk SANER ${ }^{1}$, Mert KESİCi'2 ${ }^{2}$ Mohammed MAHDI ${ }^{3}$, Yusuf YASLAN ${ }^{4}$, V. M. İstemihan GENÇ ${ }^{* 5}$
}

1,2,5İstanbul Teknik Üniversitesi, Elektrik-Elektronik Fakültesi, Elektrik Müh. Bölümü, 34469, İstanbul, Türkiye ${ }^{1}$ (ORCID: https://orcid.org/0000-0002-5149-523X)

${ }^{2}$ (ORCID: https://orcid.org/0000-0001-5344-9125)

5(ORCID: https://orcid.org/0000-0001-7077-8895)

3İstanbul Bilişim ve Akıllı Kent Teknolojileri A.Ş. (İSBAK A.Ş.), 34418, İstanbul, Türkiye

${ }^{3}$ (ORCID: https://orcid.org/0000-0002-1535-4907)

4İstanbul Teknik Üniversitesi, Bilgisayar ve Bilișim Fakültesi, Bilgisayar Müh. Bölümü, 34469, İstanbul, Türkiye ${ }^{4}$ (ORCID: https://orcid.org/0000-0001-8038-948X)

\section{Anahtar Kelimeler}

Geçici hal kararlılı̆̆ı, Sinıflandırma,

Kestirim,

Güç sistemleri,

Makine öğrenmesi
Özet: Geçtiğimiz yıllarda, dünya çapında farklı güç sistemlerinde, çok sayıda geniș çaplı enerji kesintileri meydana gelmiş, bu kesintiler milyonlarca tüketicinin olumsuz etkilenmesine neden olmuş ve büyük miktarda mali zararlara neden olmuştur. Elektrik güç sistemi tasarımı ve işletmesinde kritik bir role sahip sistem kararlılığı, günümüzdeki önemini korumaktadır. Bir güç sisteminin kararlılık durumunu gerçek zamanlı olarak izlemek, sistem çökmelerini önlemede birincil öneme sahip bir görev olarak kabul edilmektedir. Şebekenin kararlılık durumunun gerçek zamanlı olarak izlenmesi, geniş alan izleme, koruma ve kontrol sistemlerinin verimliliği açısından önemli bir fonksiyondur. Bu fonksiyon ile düzeltici kontrol eylemlerinin zamanında gerçekleştirilebilmesi sağlanabilir. $\mathrm{Bu}$ çalışmada, güç sisteminde meydana gelebilecek arızalar öncesinde fazör ölçüm birimlerinden alınan gerilimlere ait genlik ve açıların yanı sıra, arızanın temizlenme süresi ve arızanın temizlenmesi için devreden çıkarılan iletim hattına ait topoloji bilgileri de kullanılarak, geçici hal kararsızlıklarının kestirimi, karar ağaçlarına dayalı iki farklı yöntem ile gerçekleştirilmiştir. Önerilen makine öğrenmesi modellerinin bașarımları ve etkinlikleri 29 jeneratörlü 127 baralı WSCC (Batı Eyaletleri Koordinasyon Kurulu) test sisteminde uygulanarak gösterilmiștir.

\section{Early Prediction of Transient Instabilities Based on Pre-Fault Phasor Measurements using Decision Tree-based Methods}

\section{Keywords}

Transient instabilities,

Classification,

Prediction,

Power systems,

Machine learning

\begin{abstract}
In recent years, many blackouts occurred in power systems of different parts of the world, affecting millions of people and causing great economic losses. Power system stability, which has a critical role in the design and operation of electrical power systems, maintains its importance today. Monitoring the stability status of a power system in real time is regarded as a primary task in preventing system blackouts. This allows of a sufficient amount of time to take appropriate corrective control actions. In this study, the pre-fault voltage magnitudes and angles taken from the phasor measurement units (PMU), clearing time of the fault and topology information of the transmission line that has been tripped for clearing the fault are used to predict the transient instabilities by two different methods based on the decision trees. The success and the effectiveness of the proposed machine learning models are shown as they are applied to the 127-bus Western Systems Coordinating Council (WSCC) test system.
\end{abstract}

\section{Giriş}

Artan yük talebine karşın yeni iletim hatlarının tesisi zorluğu yanı sıra, değişen üretim ve yük tipleri ile yeni pazar gereksinimleri gibi pek çok nedenden ötürü, güç sistemlerinin üzerinde hali hazırda bulunan baskının daha da artacağı öngörülmektedir. $\mathrm{Bu}$ koşullar altında çeşitli bozucu etkilerin meydana 
gelmesi ve bu bozunumların güç sistemlerini kararlılık sınırlarının üzerinde zorlama olasılığı, oldukça yüksektir. Bu nedenle, elektrik güç sistemi tasarımı ve işletmesinde her zaman dikkate alınması gereken sistem kararlılı̆̆ çalışmalarının önemi, gün geçtikçe artmaktadır. Bir güç sisteminin kararlılık durumunu gerçek zamanlı olarak izlemek, elektrik kesintilerini önlemede birincil öneme sahip bir görev olarak kabul edilmektedir.

Geçtiğimiz yllarda, dünya genelinde farklı güç sistemlerinde, birbirine benzer nedenlerden dolayı meydana gelen geniş çaplı enerji kesintileri, milyonlarca tüketicinin olumsuz etkilenmesine ve büyük miktarda ekonomik zararlara neden olmuştur. Türkiye'de Mart 2015'te meydana gelen sistem çökmesi de geniş çaplı sistem çökmelerine örnek olarak gösterilebilir. Aşırı yüklenmiş bir iletim hattının planlanmış bir bakım kapsamında devreden çıkarılması ile meydana gelen bu geniş çaplı sistem çökmesi, 10 saate yakın bir süre 76 milyon tüketiciyi elektriksiz bırakmıştır. İlk başta, bu hattın devreden çıkarılması, Türkiye güç sisteminin batı ve doğu kısımlarının birbirinden ayrılmasına neden olmuş ve sonrasinda ise, Türkiye, Avrupa güç sisteminden ayrılmış ve Türkiye elektrik şebekesinin batı bölgesi ve doğu bölgesi kararsızlığa giderek çökmüştür. Geçtiğimiz on yıllarda, dünyanın birçok farklı yerinde meydana gelen diğer sistem çökmelerine örnek olarak 1965 yılında ABD'nin kuzeydoğusunda, 1996'da ABD'nin batısında, 1999'da Brezilya'da, 2003'te İtalya'da, 2003 'te İsveç'te, 2004'te Bangladeş'te ve 2012'de Hindistan'da meydana gelen olaylar gösterilebilir. Tarihte en büyük çaplı sistem çökmesi Temmuz 2012'de Hindistan'da meydana gelmiş ve iki gün boyunca 620 milyon kullanıcı aralıksız iki gün süre ile elektriksiz kalmıştır [1].

Büyük çaplı elektrik kesintileri sonucunda ortaya çlkan ekonomik etkiler, güç sistemlerinin dinamik güvenliğinin önemini güç geçtikçe arttırmaktadır. Yaşanan tüm sorunlar, güç sisteminin kararlılı̆̆ını kaybederek büyük çapta arızalara ve sistem çökmelerine sebep olabilecek olayların engellenmesi için geniş çaplı şebeke izleme ve kontrol yöntemlerine duyulan ihtiyacı ortaya koymaktadır. Bu kapsamda, güç sistemlerinin durumsal farkındalık kabiliyetlerinin de iyileştirilmesi gerekmektedir. Geçtiğimiz yıllarda meydana gelen teknolojik gelișmeler ile birlikte gün geçtikçe kullanımı artan fazör ölçüm birimleri (FÖB), güç sistemi operatörlerine güç sisteminin izlenmesinde, korunmasında ve kontrol edilmesinde çok büyük bir esneklik kazandırmıștır. FÖB'lerin eşzamanlı ve yüksek örnekleme hızına sahip ölçme yeteneği, güç sistemlerinde durumsal farkındalığın iyileştirilmesi için kritik bir teknoloji olarak görülmelerini de beraberinde getirmektedir.

Güç sisteminde meydana gelen önem derecesi yüksek bir arıza sonrasında güç sisteminin kararsızlığa gitmesini önlemek için, geniş alan izleme, koruma ve kontrol sistemleri dünya çapındaki farklı şebekelerde kullanılmaktadır. $\mathrm{Bu}$ sistemler, şebekenin anlık durumunu izlemek için FÖB ölçümlerinden yararlanmakta ve kritik arızalar sonrasında güç sisteminde arıza yayılmalarının önüne geçmektedir. FÖB ölçümleri saniyede 30 ile 120 arasında değişen sayıda örnek toplayarak, geniş alan izleme koruma ve kontrol sisteminin güç sistemi dinamiklerini ve salınımlarını yakalamasını sağlamaktadır. Bu örnekleme hızl, güç sisteminin bozucu etkiler meydana geldiğindeki davranışının analizini ve en hızlı şekilde gereken iyileştirici kontrol eylemlerinin uygulanması için yeterli olmaktadır [2].

Geçici hal kararlılı̆̆ının kestirimi, beklenen bir kararsızlık durumuna karşı düzeltici kontrol eylemlerinin uygulanması için gerekli ve yeterli zamanın kazanılması açısından büyük bir öneme sahiptir. Veri madenciliği ve makine öğrenmesi teknikleri, büyük miktarlarda yüksek boyutlu verilerle bașa çlkmak için geliștirilmiș ve bunların bir kısmı, elektrik güç sistemlerinde FÖB'ler üzerinden toplanan geniş alan ölçümlerine uygulanmıştır [3]. Güç sistemlerinde geçici hal kararlılığının kestirimi için literatürde birçok çalışma gerçekleştirilmiştir. Yapılan çalıșmalardaki yaklașımları, zaman tanım bölgesi benzetim çalışmaları, geçici enerji fonksiyonu yöntemleri ve makine öğrenmesi tabanlı yöntemler olarak üç kategoride incelemek mümkündür. Geleneksel ve kesin bir yaklaşım olan zaman tanım bölgesi benzetim çalışmaları, sistem modelinin ve çalışma koşulunun doğru bilgisine duyulan ihtiyacın yanı sıra ağır bir hesaplama yükünü beraberinde gerektirmektedir [4, 5]. Enerji fonksiyonu tabanlı yaklaşımlarda ise, kullanılabilecek model kısıtları yanı sıra, çeşitli hesaplama yükü ve zorlukları altında kararlılık değerlendirmesi yapılabilmektedir [6]. Eşit alan kriteri tabanlı yöntemler, diferansiyel denklemleri çözmeden, çok makinalı sistemleri sonsuz güçlü baraya bağlı tek makina sistemi olarak temsil ederek geçici hal kararlılı̆̆ının değerlendirilmesine olanak sağlamaktadır. Sistemin eşdeğer modeline ihtiyaç duyulması ve sadece mekanik dinamikleri temsil eden klasik jeneratör modelinin kullanımına izin verilmesi, bu yaklaşımlarda karşılaşılan başlıca dezavantajlardır [7, 8].

Makine öğrenmesine dayalı yaklaşımlar, FÖB ölçümlerini kullanan çevrimiçi geçici hal kararlılığının değerlendirilmesi probleminin çözümü için umut veren yenilikçi yöntemler olarak kabul edilmektedir. Genel olarak, makine öğrenmesi tabanlı bir yaklaşım, önceden bilinmeyen örüntü veya değişkenler arasındaki sistematik ilişkileri çıkarmak için büyük miktarda veriyi otomatik olarak araştırmak üzere tasarlanmıș analitik bir süreçtir. Bu örüntüler veya ilișkiler daha sonra gelecek tahmini için kullanılabilmektedir. Genel olarak, bu süreç, çevrimdışı olarak bir veri kümesinin hazırlanması, 
modelin oluşturulması ve tahminlerin yapılması için modelin yeni verilere uygulanması aşamalarından oluşmaktadır.

Literatürde geçici hal kararlılığının kestirimi için makine öğrenmesi tabanlı çeşitli çalışmalar bulunmaktadır. Geçici hal kararlılığının kestirimi yaklaşımı hem önleyici hem de düzeltici kontrol yöntemleri için uygulanmıştır. Kullanılacak olan makine öğrenmesi modelinin çevrimdıșı așamada oluşturulmasındaki temel fark, beklenmeyen durumları tanımlayan parametrelerdir. Önleyici kontrol için kullanılabilecek parametreler, arızanın tipi ve konumu gibi arızaya bağımlı değişkenleri ve bara gerilim genlikleri, gerilim açları, jeneratörlerin aktif ve reaktif güç çıkışları, yüklerin aktif ve reaktif güç değerleri gibi arıza öncesi sistemden alınan arızadan bağımsız değişkenleri içermektedir [9, 19]. Gerçek zamanlı olarak, arızadan bağımsız değişkenler FÖB ölçümlerinden elde edilerek, önceden hazır hale getirilen makine öğrenmesi modeline girdi olarak verilmektedir. Düzeltici kontrol uygulamaları için ise, çevrim dışı veri kümesindeki beklenmeyen durumları tanımlayan parametreler, FÖB ölçümlerinden alınan jeneratör rotor açıları ve hızları, gerilim genlikleri ve açılarıdır. Yapay sinir ağları, doğrusal olmayan örüntü tanıma problemini çözme kabiliyeti sebebi ile birçok çalışmada kullanılmıştır $[9,13]$. Karar ağaçları da, yorumlanmalarının kolay olmasından dolayı ve veri tabanı sistemleri ile kolayca entegre edilebilmelerinden dolayı geçici hal kararlılığının kestirimi çalışmalarında kullanılmıştır $[14,18]$. Güç sistemlerinde uzun yıllardan beri farklı alanlarda uygulaması olan destek vektör makineleri [19] ve son yıllarda kullanımı artan aşırı öğrenme makineleri (extreme learning machines) [20], kullanılan diğer makine öğrenmesi modellerindendir. Ayrıca arıza sırası, öncesi ve sonrasını temsil eden belirli ölçümleri kullanan bir yaklașım da [21]'de sunulmuştur.

Şebekenin geçici hal kararlılığının arıza gerçekleşmeden önce kestirimi, geniş alan izleme, koruma ve kontrol sisteminin başarımı açısından büyük bir öneme sahiptir. Şebekenin durumsal farkındalık yeteneği şiddetli arızalar meydana geldiğinde kararsızlıkların hızla tespit edilmesi ile daha verimli hale getirilebilir. $\mathrm{Bu}$ sayede, düzeltici kontrol eylemlerinin uygulanabilmesi için gerekli ve yeterli zaman kazanılabilir. Bu çalıșmada arıza öncesinde fazör ölçüm birimlerinden alınan gerilim genliği ve gerilim açı bilgisi ile arıza temizlenme süresi ve arızanın temizlenmesi için açılan iletim hattının bağlı bulunduğu baraların numarası kullanılarak, güç sisteminde meydana gelebilecek olan geçici hal kararsızlıklarının kestirimi problemi ele alınmıştır. Söz konusu problemin çözümü için literatürde sıkça kullanılan karar ağaçları ve daha önce bu problemin çözümünde kullanılmamış olan karar ağaçları tabanlı bir topluluk öğrenme (ensemble learning) metodu olan LightGBM (Light Gradient Boosting Machine) modeli kullanılmıştır.

\section{Materyal ve Metot}

\subsection{Karar ağacı tabanlı makine öğrenmesi modelleri}

\subsubsection{Karar ağaçları}

Karar ağaçları, yüksek boyutlu bir veri uzayında sınıflandırma problemlerini çözmek için etkili bir gözetimli makine öğrenmesi (supervised learning) yöntemidir. Şekil 1'de gösterildiği üzere bir karar ağacl, her iç düğümün bir öznitelik üzerinde bir "testi" temsil ettiği akış şeması benzeri bir yapıdır. Her dal, testin sonucunu; her bir düğüm ise bir sınıf etiketini temsil etmektedir. Kökten son dügüume kadar giden yollar sınıflandırma kurallarını temsil etmektedir. Karmaşık sınıflandırma süreci, giriş verisi olarak kullanılan özniteliklere veya bunların doğrusal kombinasyonlarına göre birkaç "eğer-ise" sorusuna dönüştürülerek çözülmektedir.

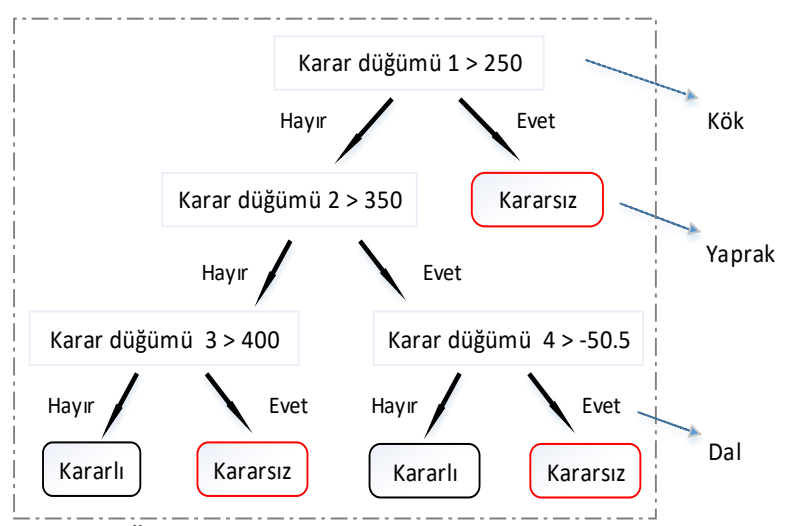

Şekil 1. Örnek bir karar ağacı yapısı

Verinin dağılımından bağımsız olan karar ağacında, ağaç yapısı en baştan sabit değildir ve verinin altında yatan işlevin karmaşıklığına bağlı olarak, dallar ve yapraklar eklenerek ağaç büyümektedir.

Karar ağaçlarını iyi bir başarımla eğitebilmek için, öncelikle yeterince sayıda örnekten oluşan bir veri kümesi oluşturulmalıdır. Her bir durum, bir öznitelik vektörü (örneğin, jeneratörlerin aktif güç çıkışları, baraların gerilim genliği ve açları vb.) ile birlikte bir karar etiketi (kararlı veya kararsız) ile temsil edilir. Karar ağacı daha sonra bu hedefi en etkili ve doğrudan etkileyen kritik öznitelikleri tanımlayarak bu amaç için bir sınıflandırma modelini temsil edecek şekilde tasarlanmıştır [22].

\subsubsection{LightGBM (hızlı bir yön türevi hızlandırıcı makina) modeli}

LightGBM, karar ağaçları tabanlı hızlı, dağıtık, yüksek başarımlı bir topluluk öğrenme yöntemidir. Topluluk öğrenme yöntemleri, birden fazla model oluşturan ve daha sonra gelişmiş sonuçlar elde etmek için bunları birleștiren tekniklerdir. Topluluk yöntemleri genellikle tek bir modelden daha doğru çözümler üretmektedir. 
"Güçlendirme" (boosting) terimi, zayıf modelleri güçlü modellere dönüştürebilen bir algoritma ailesini tanımlamak için kullanılmaktadır. Güçlendirme, her modelin aynı veri kümesine göre eğitilmesi, ancak örneklerin ağırlıklarının son tahminin hatalarına göre ayarlanmasıyla bir grup oluşturmaktadır. Güçlendirmede ana prensip, tahmin edilmesi zorlu örneklere odaklanmak için modelleri zorlamaktır. LightGBM modeli de birçok zayıf karar ağacından oluşmuş güçlü bir yön türevini hızlandırıcı (gradient boosting) model çeşididir. Torbalamadan (bagging) farklı olarak, birbirini izleyen sıralı bir yöntemdir.

Her bir karar ağacını eğitirken ve verileri ayırırken ağacın seviyesine odaklı (level-wise) ve ağacın yapraklarına odaklı olarak (leaf-wise) kullanılabilecek iki strateji vardır. Şekil 2'te görüldügü üzere, seviye odaklı durumda ağaç büyürken ağacın dengesi korunurken, Şekil 3'te ise yaprak odaklı strateji, kaybı en çok azaltan yaprağı bölmeye devam etmektedir.

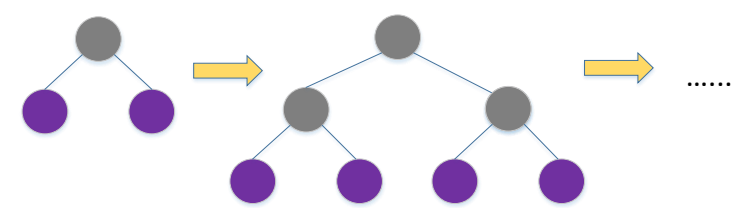

Şekil 2. Ağaç seviyesine odaklı büyüme stratejisine bir örnek

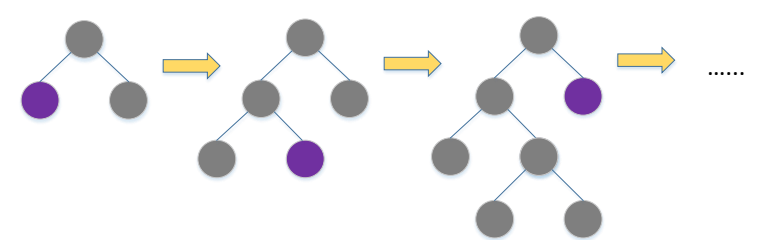

Şekil 3. Ağaç yapraklarına odaklı büyüme stratejisine bir örnek

LightGBM'in yaprak odaklı olarak büyüyen ağaç yapısı, sadece belirli bir daldaki kayıpları değil, tüm kayba olan katkılarına bağlı olarak bölünmeleri (split) seçer ve çoğu zaman daha az hata oranına sahip ağaçları, derinlik odaklı olarak büyüyen diğer topluluk öğrenme modellerine göre daha hızlı öğrenmektedir [23]. Yaprak odaklı büyüme stratejisi, seviye odaklı eğitimin yapabildiği herhangi bir ağacı oluşturabilirken, bunun tersi geçerli olmamaktadır. $\mathrm{Bu}$ özelliklerinden dolayı, LightGBM modeli aşırı öğrenmeye yatkın olmasına karşın seviye odaklı öğrenme algoritmalarına göre daha esnektir. Özellikle büyük veri kümeleri için daha iyi sonuç vermektedir.

Bir karar ağacını eğitmek için gereken süre, değerlendirilmesi gereken bölünme sayısıyla orantılıdır. Çoğu zaman, bölünmedeki küçük değişiklikler ağacın başarımında büyük bir fark yaratmaz. Histogram tabanlı yöntemlerden olan LightGBM modeli, Şekil 4'te gösterildiği gibi öznitelikleri bir dizi sepete (bin) gruplayarak ve öznitelikler yerine sepetlerde bölme yaparak bu durumdan yararlanmaktadır.

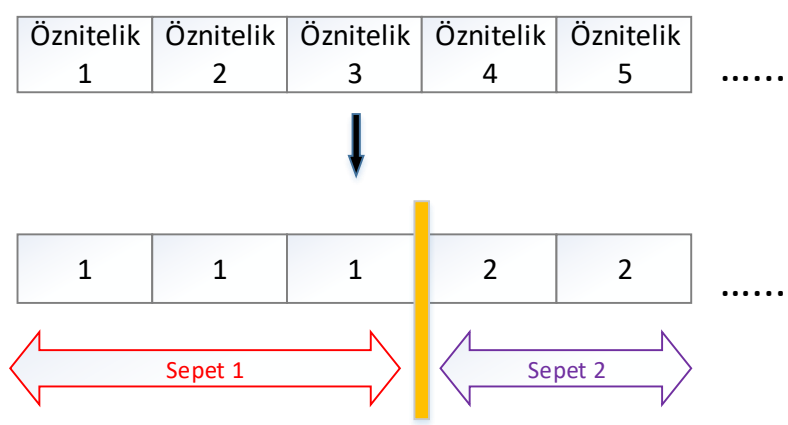

Şekil 4. Özniteliklerin sepetlenmesine bir örnek

$\mathrm{Bu}$ özellik, her bir ağacın oluşturulmasından önce öznitelikleri sepetleyebildiğinden dolayı, hesaplama karmaşıklığını azaltarak, eğitim süresinde ciddi azalmalara neden olmaktadır [24].

\subsection{Geçici hal kararsızlığının tespiti}

Güç sisteminde gerçekleşen bir arıza sonrası dinamik güvenlik değerlendirmesi ve geçici hal kararlık durumunun tespiti amaciyla önerilen makine öğrenmesi sınıflandırıcı için öncelikle bir öğrenme veri kümesi elde edilmesi gerekmektedir. Veri kümesinin oluşturulması ve önerilen sınıflandırıcının başarımının incelenmesi için 127 bara ve 37 jeneratörden oluşan WSCC güç sistemi modeli ele alınmıştır [25]. Söz konusu güç sisteminin tek hat şeması Şekil 5'te verilmiştir.

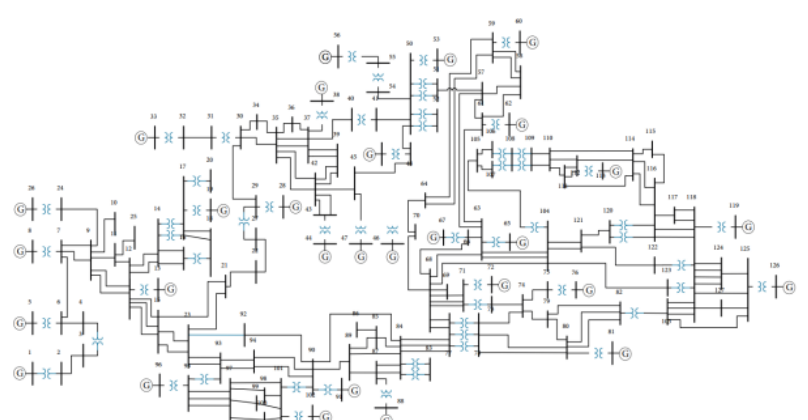

Şekil 5. Ele alınan 127-baralı 37-jeneratörlü WSCC test sistemi [26]

Veri kümesinin elde edilmesinden sonra, öğrenme karmaşıklığını azaltmak adına bir öznitelik seçimi süreci gerçekleştirmek önemlidir. Öznitelik seçimi ve eğitim sürecinin tamamlanmasından sonra, çeşitli ölçütler kullanılarak sınıflandırıcı başarımının denetlenmesi gerekmektedir.

\subsubsection{Veri kümesinin elde edilmesi}

Güç sisteminde her barada bulunduğu varsayılan FÖB'lerden alınacak arıza öncesi gerilim genliği ve açısı ölçümleri ile birlikte, arızanın temizlenme süresi ve arızanın temizlenmesi için açılan iletim hattının bağlı bulunduğu baraların numarası, öznitelik olarak 
kullanılarak bir veri kümesi oluşturulmuştur. Kullanılacak öznitelikler, Tablo 1'de özetlenmiştir.

Tablo 1. Veri kümesinin için alınan öznitelikler

\begin{tabular}{ll}
\hline \multicolumn{1}{c}{ Öznitelikler } & \multicolumn{1}{c}{ Açıklama } \\
\hline$V_{1}^{j}, \ldots, V_{i}^{j}, \ldots, V_{127}^{j}$ & $j$. örnek $i$. bara arıza öncesi gerilim genliği \\
$\delta_{1}^{j}, \ldots, \delta_{i}^{j}, \ldots, \delta_{127}^{j}$ & $j$. örnek $i$. bara arıza öncesi gerilim açısı [] \\
$b_{1}^{j}, b_{2}^{j}$ & $j$. örnek açllan hat bara numaraları \\
$t^{j}$ & $j$. örnek arıza temizlenme süresi [periyot] \\
\hline
\end{tabular}

Makine öğrenmesi tabanlı sınıflandırıcının eğitimi için kullanılacak veri kümesi, DSATools dinamik güvenlik değerlendirmesi yazılım paketinde bulunan TSAT benzetim yazılımı ile oluşturulmuştur [27]. Veri kümesi oluşturulurken, arıza öncesinde güç sisteminin işletilebileceği pek çok olası çalışma noktası kurgulanmıştır. Her bir çalışma noktasında, sistemde bulunan tüm baralarda ayrı ayrı meydana gelecek üç fazlı kısa devreler dikkate alınmıştır. Bu kısa devrelerin, arızanın meydana geldiği baraya bağlı bir iletim hattının devreden çıarılmasıyla giderildiği düşünülmüștür. Her bir bozucu etki için arıza temizlenme süresinin (bir başka değişle, arızanın gerçekleşmesinden hattın devreden çıkarılmasına kadar geçen zamanın) 4 veya 8 periyot olduğu durumlar ele alınmıştır.

Bahsedilen yaklaşımla üretilen ve her biri 257 adet öznitelikten oluşan toplam 9840 adet örnek, arıza sonrası sistem güvenlik durumunu ifade eden "kararlı değil" veya "kararlı" sınıfları ile etiketlenerek veri kümesi oluşturulmuştur.

\subsubsection{Sınıflandırıcı eğitimi ve öznitelik seçimi}

Öğrenme için kullanılacak veri kümesi, $x=$ $\left\{\boldsymbol{x}^{j}, r^{j}\right\}_{j=1}^{9840}$ ile gösterilsin. Burada $\boldsymbol{x}^{j}$ vektörü $j$. örnek için öznitelik değerlerini, $r^{j} \in\{0,1\}$ ise bu örnek için sınıf etiketlerini "kararlı değil" için 0 ve "kararlı" için 1 olacak şekilde ifade etmektedir. Bu veri kümesi öncelikle, etiket değerleri oranı aynı kalacak şekilde katmanlaştırılarak \%90 eğitim kümesi $x_{e \breve{\mathrm{g}}}=$ $\left\{X_{8856 \times 257}, \boldsymbol{r}_{8856 \times 1}\right\}$ ve $\% 10$ sinama kümesi $X_{\text {sin }}=$ $\left\{X_{984 \times 257}, \boldsymbol{r}_{984 \times 1}\right\}$ olmak üzere ikiye ayrilmıştır.

Eğitilecek makine öğrenmesi tabanlı sınıflandırıcının üst değişkenleri, 10 katlı çapraz geçerleme ile rastsal arama yaklaşımı uygulanarak belirlenmiştir. Rastsal arama sürecinde her bir üst değişkene, bir olasılık dağılım işlevi tanımlanmıștır. Üst değişkenler, her bir arama adımında olasılık dağılımından rastgele seçilmiştir. Sınıflandırıcı, rastgele seçilen üst değişkenler ve eğitim kümesi ile 10 katlı çapraz geçerleme kullanılarak eğitilmiştir. Çapraz geçerleme sonucu geçerleme kümeleri üzerinde elde edilen ortalama doğruluk oranları kaydedilmiştir. Bu yinelemeli süreç 1000 kere tekrarlanmış ve sonuçta en yüksek ortalama doğruluk oranını sağlayan üst değişken kümesi bulunmuştur.
Daha sonra sınıflandırıcı, bulunan üst değişken değerleri ile tüm eğitim kümesi üzerinden eğitilmiştir. Karar Ăgacı tabanlı öğrenme modellerinin önemli bir özelliği, her bir özniteliğin önem derecesini nicel olarak gösterebilmesidir. Bu önem derecesi, her bir özniteliğin ağacın katışıklığını ne kadar azalttığını ifade eden bir değerdir [28]. Önem derecesi sıfır olan öznitelikler veri kümesinden çıkartılarak indirgenmiş eğitim kümesi $\bar{\chi}_{e \breve{g}}=$ $\left\{\bar{X}_{8856 \times k_{1}}, \boldsymbol{r}_{8856 \times 1}\right\}$ ve sinama kümesi $\bar{X}_{\text {sin }}=$ $\left\{\bar{X}_{984 \times k_{1}}, \boldsymbol{r}_{984 \times 1}\right\}$ elde edilmiştir. Burada $k_{1}: k_{1} \leq 257$, önem derecesi sıfırdan büyük olan öznitelik sayısını ifade etmektedir.

İndirgenmiş veri kümesi üzerinden bir defa daha boyut azaltma gerçekleştirmek adına, Özçağrılı Öznitelik Seçimi (ÖÖS) yaklaşımı uygulanmıştır. ÖÖS, öznitelik önem derecelerini kullanarak mevcut öznitelik kümesinden her adımda belli bir sayıda öznitelik çlkartarak daha az elemanlı bir öznitelik kümesi oluşturan bir yaklaşımdır [29]. İndirgenmiş eğitim kümesindeki tüm özniteliklerin kullanılmasından, yalnızca bir adet öznitelik kullanılmasına kadar olası tüm öznitelik altkümeleri ÖÖS ve 10 katlı çapraz geçerleme kullanılarak denenmiştir. Her bir öznitelik alt kümesi için elde edilen çapraz geçerleme doğruluk oranlarının ortalaması ve değişintisi hesaplanmıștır. En yüksek doğruluk ortalaması ve en az değișintiyi sağlayan öznitelik kümesi, nihai sınıflandırıcıda kullanılmak üzere seçilmiştir.

ÖÖS ile ikinci defa indirgenen eğitim kümesi $\overline{\bar{X}}_{e \breve{g}}=$ $\left\{\overline{\bar{X}}_{8856 \times k_{2}}, \boldsymbol{r}_{8856 \times 1}\right\}$, üst değişkenleri en iyileştirilmiş sınıflandırıcının eğitiminde kullanılmıștır. Eğitilmiş sınıflandırıcının başarımı, eğitim sürecinde kullanılmayan indirgenmiş sınama kümesi $\overline{\bar{X}}_{\text {sın }}=$ $\left\{\overline{\bar{X}}_{984 \times k_{2}}, \boldsymbol{r}_{984 \times 1}\right\}$ üzerinden denetlenmiştir. Burada $k_{2}: k_{2} \leq k_{1} \leq 257$, sinıflandırıcıda kullanılacak öznitelik sayısını ifade etmektedir. Önerilen sınıflandırıcı eğitimi ve öznitelik seçimi sürecinin akış diyagramı, Şekil 6'da verilmiştir.

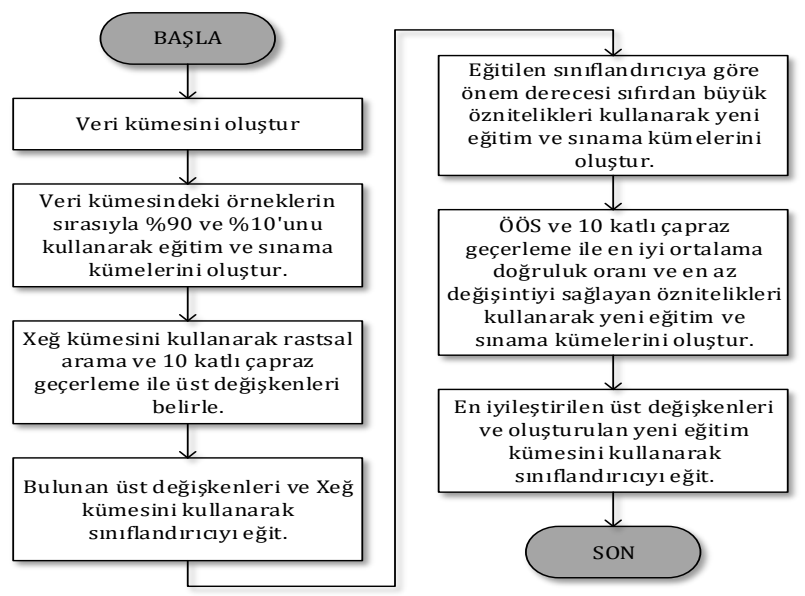

Şekil 6. Önerilen sınıflandırıcı eğitimi ve öznitelik seçimi süreci 


\subsubsection{Sinıflandırıcıların sınanması}

Ele alınan her iki sınıflandırıcı da, öncelikle tüm öznitelikleri içeren $\mathcal{X}_{e \breve{g}}$ kümesi ile eğitilmiş ve $\mathcal{X}_{s i n}$ kümesi ile sınanmıştır. Bu iki sınıflandırıcı daha sonra öznitelik seçimi sonrası bulunan $\overline{\bar{X}}_{e \breve{g ̆ ~}}$ kümesi ile eğitilmiş ve $\overline{\bar{X}}_{s i n}$ kümesi ile sınanmıştır. Böylelikle hem sinıflandırıcıların, hem de kullanılan öznitelik seçim sürecinin başarımı denetlenebilmiştir.

Sınıflandırıcıların başarımı, literatürde sıklıkla kullanılan doğruluk, kesinlik ve F1 ölçütleri üzerinden gösterilmiştir. Sınama süreci, Şekil 7 ile görsel olarak özetlenmiştir.
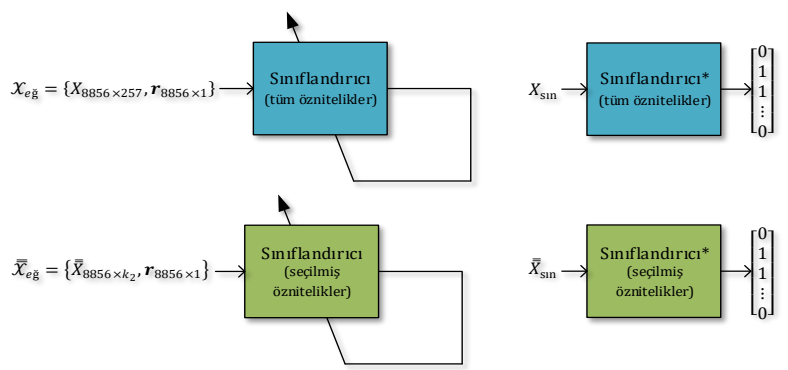

Şekil 7. Sinıflandırıcıların sınanma süreci (yıldız (*) simgesi, sınıflandırıcının eğitilmiş olduğunu ifade etmektedir)

\section{Bulgular}

Karar Ağacı ve LightGBM tabanlı sinıflandırıcıların dörder üst değişkeni için her değişkene uygun sınırlar tanımlanarak birer kesikli tekdüze dağılım işlevi belirlenmiştir. Buna göre ele alınan üst değişkenler ve rastsal arama ile en iyileştirilmiş değerleri Tablo 2'de verilmiştir.

Tablo 2. Rastsal arama için ele alınan üst değişkenler ve en iyileștirilmiș değerleri

\begin{tabular}{cll}
\hline Sınıflandırıcı & Üst Değişken & Seçilen Değer \\
\hline \multirow{4}{*}{ Karar Ağacı } & criterion & 'gini' \\
& max_depth & 'none' \\
& min_samples_leaf & 1 \\
& min_samples_split & 2 \\
\hline \multirow{2}{*}{ LightGBM } & n_estimators & 300 \\
& num_leaves & 20 \\
& learning_rate & 0,7 \\
& max_bin & 350 \\
\hline
\end{tabular}

Tüm özniteliklerin kullanıldığı $x_{e \breve{g ̆ ~}}$ kumesi ile yapılan eğitim sonrasında elde edilen öznitelik önem derecelerine bakıldığında Karar Ağacı'nda 67, LightGBM'de ise 133 adet sıfırdan büyük önem derecesine sahip öznitelik bulunmuştur. Daha sonra Karar Ağacı için $k_{1}=67$ ve LightGBM için $k_{1}=133$ değerlerine sahip $\bar{X}_{e \check{g ̆ ~}}$ kümelerine uygulanan ööS ile, 1 ila $k_{1}$ arası elemanlı öznitelik kümeleri belirlenmiştir. Bu kümelerle yapılan 10 katlı çapraz geçerleme sonucu elde edilen en yüksek 5 doğruluk ortalaması ve değişintileri Tablo3'te verilmiştir.
Tablo 3. Farklı öznitelik kümeleri için elde edilen 10 katlı çapraz geçerleme sonuçları

\begin{tabular}{cccc}
\hline \multirow{3}{*}{ Sınıflandırıcı } & $\begin{array}{c}\text { Öznitelik } \\
\text { Sayısı }\end{array}$ & $\begin{array}{c}\text { Doğruluk } \\
\text { Ortalaması } \\
{[\%]}\end{array}$ & $\begin{array}{c}\text { Doğruluk } \\
\text { Değişintisi } \\
{\left[10^{-4}\right]}\end{array}$ \\
\hline \multirow{3}{*}{ Karar Ağacı } & 18 & 98,159 & 0,160 \\
\cline { 2 - 4 } & 27 & 98,159 & 0,195 \\
\cline { 2 - 4 } & 13 & 98,080 & 0,208 \\
\cline { 2 - 4 } & 17 & 98,080 & 0,226 \\
\hline \multirow{3}{*}{ LightGBM } & 45 & 98,080 & 0,236 \\
\cline { 2 - 4 } & 11 & 98,938 & 0,152 \\
\cline { 2 - 4 } & 10 & 98,927 & 0,140 \\
\cline { 2 - 4 } & 36 & 98,927 & 0,114 \\
\hline
\end{tabular}

Tablo 3'e bakıldığında, Karar Ağacı için en yüksek doğruluk ortalaması ve en düşük değişintiyi veren öznitelik sayısının 18 olduğu görülmektedir. LightGBM için ise en yüksek doğruluk ortalamasını sağlayan öznitelik sayısı 11, en düşük değişintiyi sağlayan öznitelik sayısı ise 36 'dır. Yapılan t-testi sonucu bu iki rastsal değişken arasında istatistiksel açıdan önemli bir fark olmadığı saptandığından, daha düşük olan öznitelik sayısı olan 11 tercih edilmiştir. Her iki sınıflandırıcı için seçilen öznitelikler, Tablo 4'te gösterilmiştir.

Tablo 4. Sınıflandırıcılar için seçilen öznitelikler

\begin{tabular}{ll}
\hline Sinıflandırıcı & \multicolumn{1}{c}{ Seçilen Öznitelikler } \\
\hline & $V_{3}^{j}, V_{10}^{j}, V_{26}^{j}, V_{30}^{j}, V_{37}^{j}, V_{45}^{j}, V_{57}^{j}, V_{66}^{j}, V_{71}^{j}$ \\
& $\delta_{3}^{j}, \delta_{15}^{j}, \delta_{24}^{j}, \delta_{27}^{j}, \delta_{28}^{j}, \delta_{45}^{j}$ \\
& $b_{1}^{j}, b_{2}^{j}$ \\
& $t^{j}$ \\
\hline & $V_{1}^{j}, V_{8}^{j}, V_{24}^{j}, V_{51}^{j}$ \\
& $\delta_{1}^{j}, \delta_{12}^{j}, \delta_{13}^{j}, \delta_{15}^{j}$ \\
& $b_{1}^{j}, b_{2}^{j}$ \\
& $t^{j}$ \\
\hline
\end{tabular}

Seçilen özniteliklerden gerilim genliği ve açıların ölçüldüğü baraların ele alınan güç sistemindeki konumları Karar Ağacı için Şekil 8 ve LightGBM için Şekil 9'da verilmiştir.

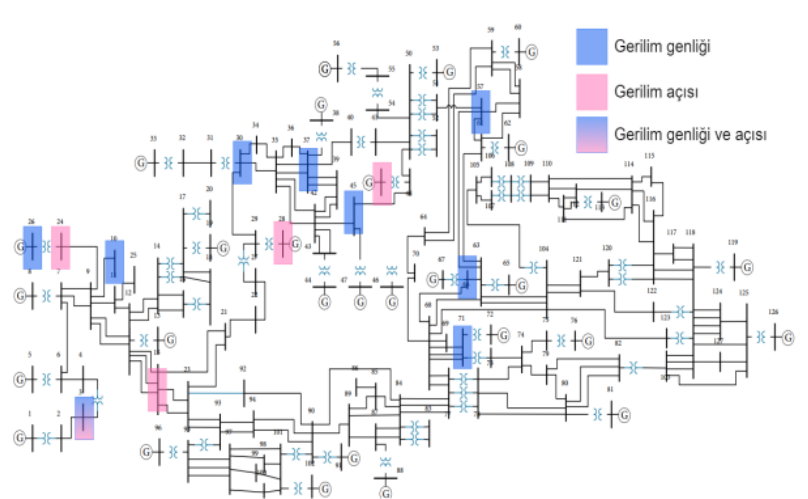

Şekil 8. Karar Ağacı için seçilen özniteliklerin ölçüldüğü baralar 


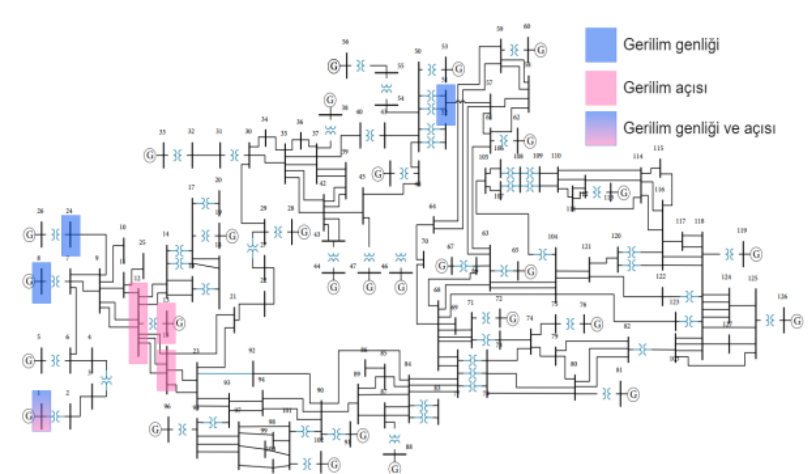

Şekil 9. LightGBM için seçilen özniteliklerin ölçüldüğü baralar

Özniteliklerin belirlenmesinden sonra Karar Ağacı ve LightGBM, sirasiyla $k_{2}=18$ ve $k_{2}=11$ değerlerine

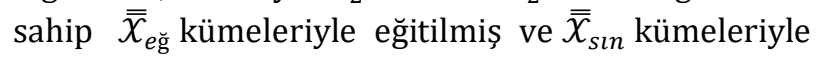
sınanmıștır. Karar Ağacı ve LightGBM'in eğitim ve sınama kümeleri ile tüm veri kümesi üzerindeki başarımları, Tablo 5'te verilen ölçütler üzerinden gösterilmiștir.

Tablo 5. Sınıflandırma tahminleri için bașarım ölçütleri

\begin{tabular}{llccc}
\hline Sınıflandırıcı & Küme & Doğruluk & Kesinlik & F1 \\
\hline \multirow{4}{*}{ Karar Ağacı } & eğitim & $\% 100$ & $\% 100$ & $\% 100$ \\
& sınama & $\% 97,86$ & $\% 97,84$ & $\% 98,48$ \\
& tümü & $\% 99,78$ & $\% 99,78$ & $\% 99,85$ \\
\hline \multirow{3}{*}{ LightGBM } & eğitim & $\% 100$ & $\% 100$ & $\% 100$ \\
& sinama & $\% 98,88$ & $\% 98,98$ & $\% 99,20$ \\
& tümü & $\% 99,89$ & $\% 99,90$ & $\% 99,92$ \\
\hline
\end{tabular}

Her iki sınıflandırıcının, ilgili veri kümeleri üzerinde gerçekleştirdiği tahminlerin doğruluk matrisleri Şekil 10 'da verilmiştir.
Kullanılan öznitelik seçimi yönteminin başarımını değerlendirmek amacıyla iki sinıflandırıcı, tüm öznitelikleri içeren $\mathcal{X}_{e \breve{g ̆ ~}}$ kümesi kullanılarak eğitilmiş ve $X_{\text {sin }}$ kümesi ile sınanmıştır. Elde edilen sonuçlar Tablo 6 'da aktarılmıştır.

Tablo 6. Tüm öznitelikler kullanılarak yapılan sınıflandırma için bașarım ölçütleri

\begin{tabular}{clccc}
\hline Sinıflandırıcı & Küme & Doğruluk & Kesinlik & F1 \\
\hline \multirow{4}{*}{ Karar Ağacı } & eğitim & $\% 100$ & $\% 100$ & $\% 100$ \\
& sinama & $\% 97,66$ & $\% 97,83$ & $\% 98,33$ \\
& tümü & $\% 99,76$ & $\% 99,78$ & $\% 99,83$ \\
\hline \multirow{3}{*}{ LightGBM } & eğitim & $\% 100$ & $\% 100$ & $\% 100$ \\
& sinama & $\% 98,58$ & $\% 98,84$ & $\% 98,98$ \\
& tümü & $\% 99,85$ & $\% 99,88$ & $\% 99,90$ \\
\hline
\end{tabular}

\section{Tartışma ve Sonuç}

$\mathrm{Bu}$ çalışmada, büyük güç sistemlerinde meydana gelen bir arıza sonrası oluşabilecek geçici hal kararsızlık durumlarının arıza öncesi bara gerilimleri ve açıları ile arıza sonrası sistemden ayrılan hattın bağlı bulunduğu bara numaraları ve arıza temizlenme süresi ölçümlerini kullanarak ağaç tabanlı sinıflandırıcilarla önceden kestirimi gerçekleștirilmiştir. Ele alınan Karar Ağacı ve LightGBM sınıflandırıcıları ile ilk olarak önem dereceleri ve Özyinelemeli Öznitelik Seçimi kullanılarak öznitelik seçimi yapılmış, daha sonra sınıflandırıcılar eğitilerek başarımları incelenmiștir.

Kullanılan öznitelik seçimi yaklaşımına göre 257 öznitelik arasından Karar Ağacı için 18, LightGBM için 11 öznitelik seçilmiştir. Her iki sınıflandırıcı için
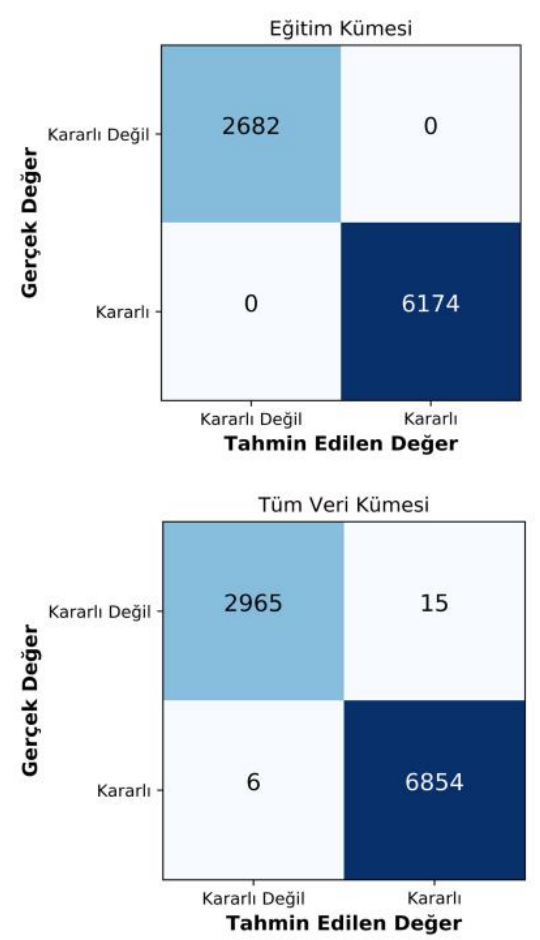
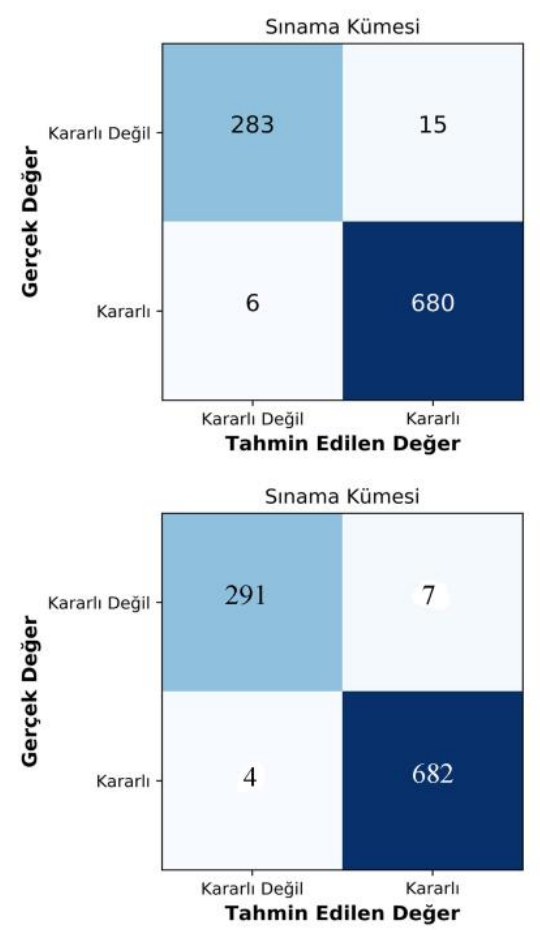
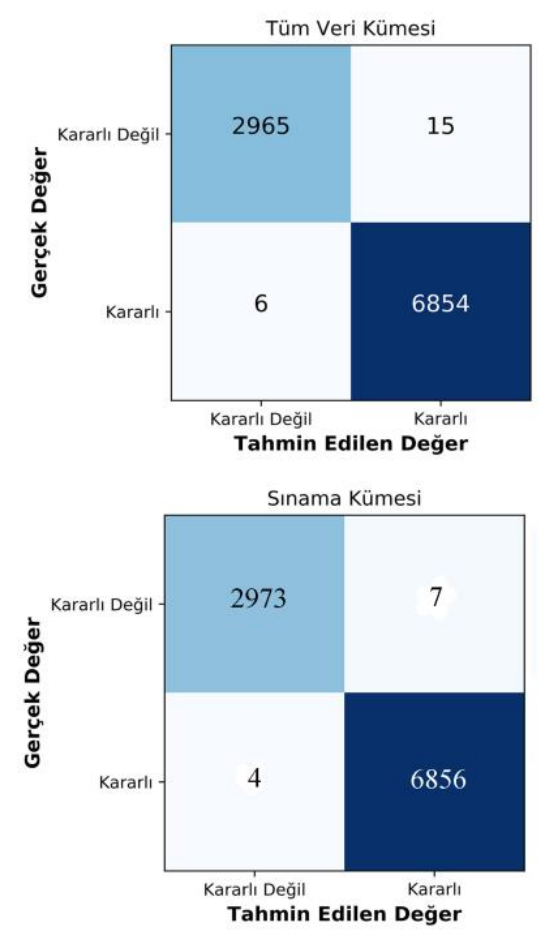

Şekil 10. Karar ağacı (üstte) ve LightGBM (altta) için eğitim, sınama ve tüm veri kümeleri üzerinde gerçekleștirilen tahminleri doğruluk matrisleri 
seçilen öznitelik kümesinde, arıza öncesi gerilim ve açıların farklı baralardan alındığı görülmektedir. Ancak açılan hat bara numaralarının ve arıza temizlenme süresinin iki sınıflandırıcı için de ortak olarak kullanılmıştır. Söz konusu bu üç öznitelik arıza sonrası sistem durumu hakkında bilgi verdiğinden, sınıflandırıcı doğruluğu için büyük önem arz etmektedir.

Seçilmiş öznitelikler ile gerçekleştirilen eğitim sonrası sınamada Karar Ağacı'nın sınama kümesi üzerinde \%97,86, LightGBM'in ise \%98,88 doğruluk oranı ile tahmin yaptığı görülmüştür. LightGBM yalnızca doğruluk oranında değil, ayrıca kesinlik ve F1 skorlarında da Karar Ağacı'na üstünlük sağladığı gösterilmiştir. Bunun ötesinde LightGBM, Karar Ağacı'ndan daha az sayıda özniteliğe ihtiyaç duymaktadır.

Önerilen öznitelik seçimi yaklaşımı ile kullanılan öznitelik sayısı \%93 ila \%95 arası azaltılarak öğrenme sürecinin karmaşıklığı düşürülmüştür. Tüm özniteliklerin kullanıldığı ve seçilmiş özniteliklerin kullanıldı̆̆ı sınıflandırma sonuçlarına bakıldığında, her iki sınıflandırıcı için de, seçilmiş özniteliklerin kullanıldığı yöntemin daha iyi sonuç verdiği görülmüştür. Bu sonuç, hem önerilen öznitelik seçimi yaklaşımının başarımını göstermekte, hem de ihtiyaç duyulan Fazör Ölçüm Birimi sayısını kayda değer biçimde azaltmaktadır.

\section{Teșekkür}

Bu çalışma, Türkiye Bilimsel ve Teknolojik Araştırma Kurumu (TÜBİTAK) Araştırma Destek Programları Başkanlığı tarafından 118E184 numaralı proje kapsamında desteklenmiştir.

\section{Kaynakça}

[1] Mohammed S. M. Mahdi. 2018. Wide-area measurement-based early prediction and corrective control for transient stability in power systems. İstanbul Teknik Üniversitesi, Fen Bilimleri Enstitüsü, Doktora Tezi, 144s. İstanbul.

[2] North American Synchrophasor Initiative (NASPI) Time Synchronization Task Force (2017). Time synchronization in the electric power system.

[3] D. Karlsson and S. . Lindahl, "Wide area protection and emergency control," in Proc. IEEE Power Eng. Soc. General Meeting, 2004, vol. 1, p. 5.

[4] Dahal, N., L. King, R., \& Madani, V. (2012). Online dimension reduction of synchrophasor data. In Transmission and Distribution Conference and Exposition (T\&D). Orlando, FL, USA: IEEE PES, 17

[5] Anderson, P. M., Fouad, A. A. (2008). Power system control and stability. Sultan Bazar, India: IEEE India.
[6] Kundur, P., Balu, N., Lauby, M. (2009). Power system stability and control. New York: McGrawHill.

[7] M. A. Pai (1989). Energy Function Analysis for Power System Stability. Boston : Kluwer Academic Publishers

[8] Ruiz Vega, D., Pavella, M. (2003). A comprehensive approach to transient stability control: part I-near optimal preventive control. IEEE Transactions On Power Systems, 18(4), 1446-1453.

[9] Srinivasan, D., Chang, C., Liew, A., \& Leong, K. (n.d.). Power system security assessment and enhancement using artificial neural network. Proceedings of EMPD 98. 1998 International Conference on Energy Management and Power Delivery

[10] C. F. Kucuktezcan, V. M. I. Genc 2010. Dynamic security assessment of a power system based on probabilistic neural networks. IEEE PES Innovative Smart Grid Technologies Conf. Europe (ISGT Europe), 11-13 October, 1-6.

[11] Lotufo, A., Lopes, M., Minussi, C. (2007). Sensitivity analysis by neural networks applied to power systems transient stability. Electric Power Systems Research, 77(7), 730-738.

[12] I. B. Sulistiawati, M. Abdillah, A. Soeprijanto 2011. Neural network based transient stability model to analyze the security of Java-Bali $500 \mathrm{kV}$ power system. International Conference on Electrical Engineering and Informatics (ICEEI), 1-6.

[13] Ferreira, W., Silveira, M., Lotufo, A., \& Minussi, C. (2006). Transient stability analysis of electric energy systems via a fuzzy ART-ARTMAP neural network. Electric Power Systems Research, 76(6-7), 466-475.

[14] V. Vittal 2012. Application of phasor measurements for dynamic security assessment using decision trees. IEEE Power and Energy Society General Meeting, San Diego, USA, 2012.

[15] Z. H. Rather, L. Chengxi, C. Zhe, C. L. Bak, \& P. Thogersen 2013. Dynamic security assessment of Danish power system based on decision trees: Today and tomorrow. IEEE PowerTech, Grenoble, France, 2013.

[16] Liu, C., Sun, K., Rather, Z., Chen, Z., Bak, C., Thogersen, P., \& Lund, P. (2014). A Systematic Approach for Dynamic Security Assessment and the Corresponding Preventive Control Scheme Based on Decision Trees. IEEE Transactions On Power Systems, 29(2), 717-730.

[17] L. Chengxi, Z. H. Rather, C. Zhe, C. L. Bak, and P. Thogersen 2013. Importance sampling based decision trees for security assessment and the corresponding preventive control schemes: The 
Danish case study, IEEE PowerTech Grenoble, France, 2013.

[18] Genc, I., Diao, R., Vittal, V., Kolluri, S. and Mandal, S. (2010). Decision Tree-Based Preventive and Corrective Control Applications for Dynamic Security Enhancement in Power Systems. IEEE Transactions on Power Systems, 25(3), pp.16111619.

[19] Moulin, L., daSilva, A., El-Sharkawi, M., \& MarksII, R. (2004). Support Vector Machines for Transient Stability Analysis of Large-Scale Power Systems. IEEE Transactions On Power Systems, 19(2), 818-825.

[20] Xu, Y., Dong, Z., Zhao, J., Zhang, P., \& Wong, K. (2012). A Reliable Intelligent System for RealTime Dynamic Security Assessment of Power Systems. IEEE Transactions On Power Systems, 27(3), 1253-1263.

[21] Mahdi, M., \& Genc, V. M. I. (2018). Post-fault prediction of transient instabilities using stacked sparse autoencoder. Electric Power Systems Research, 164, 243-252.

[22] L. Breiman, J. Friedman, R. A. Olshen, \& C. J. Stone 1984. Classification and Regression Trees. Belmont, CA: Wadsworth.

[23] Shi, H. 2007. Best-first Decision Tree Learning. The University of Waikato, Yüksek Lisasns Tezi, Hamilton, New Zealand.
[24] Meng, Q., Ke, G., Wang, T., Chen, W., Ye, Q., Ya, Z., \& Liu, T. (2016). A Communication-Effcient Parallel Algorithm for Decision Tree. In 30th International Conference on Neural Information Processing Systems. Barcelona, Spain, 12711279.

[25] Fan, D. 2008. Synchronized Measurements And Applications During Power System Dynamics. Virginia Polytechnic Institute and State University, Doktora Tezi, 182s, Virginia.

[26] Beyranvand, P. , Genç, V. M. I. , Çataltepe, Z. 2018. Multilabel learning for the online transient stability assessment of electric power systems. Turkish J. Electr. Eng. Comput. Sci, 26(2018), 2661-2675.

[27] DSATools. 2018. Dynamic Security Assessment Software Package. http://www.dsatools.com (Erişim Tarihi: 19.10.2018)

[28] Louppe, G., Wehenkel, L., Sutera, A., Geurts, P. 2013. Understanding variable importances in forests of randomized trees. 6th International Conference on Neural Information Processing Systems. Nevada, 431-439.

[29] Guyon, I., Weston, J., Barnhilll, S. 2002. Gene Selection for Cancer Classification using Support Vector Machines. Machine Learning, 46(2002), 389-422. 